\title{
PREVALENSI DIABETES MELITUS TIPE 2 DENGAN KEJADIAN HIPERTENSI DI POLIKLINIK PENYAKIT DALAM RS PERTAMEDIKA UMMI ROSNATI
}

\author{
Hanief Al-Hadi ${ }^{1}$, Zurriyani², Said Aandy Saida² \\ ${ }^{1}$ Departemen IImu Penyakit Dalam Fakultas Kedokteran Universitas Abulyatama \\ ${ }^{2}$ Program Studi Kedokteran Fakultas Kedokteran Universitas Abulyatama \\ [email korespondensi: haniefalhadi@gmail.com]
}

\begin{abstract}
Prevalence of Type 2 Diabetes Melitus and The Incidence of Hypertension in the Internal Medicine Polyclinic at Pertamedika Ummi Rosnati Hospital. Diabetes melitus type 2 is a worldwide disease related to uncontrolled blood sugar levels. If this disease isnt handled properly, complications may arise. One of the complications is hypertension, therefore the aim of this study is to determine prevalence of type 2 diabetes melitus with incidence of hypertension in internal medicine polyclinics in Pertamedika Ummi Rosnati Hospital. This study used an observational descriptive method and cross-sectional approach with a sample of 126 respondents. Sampling technique used total sampling with directional interviews. To determine the prevalence, a descriptive approach was used (univariate analysis). The results showed that the prevalence of hypertension in patients with type 2 diabetes melitus (46.8\%) from 126 samples, Compared according to sex, women has higher prevalence than men, namely as many as $(61 \%)$. Prevalence based on age showed that most prevalent age groups are 40-49 years and 50-59 years each consist of (32.2\%). As for prevalence based on duration of type 2 diabetes melitus, most of them have suffered from type 2 diabetes melitus Most of them had type 2 diabetes melitus $<5$ years, as many as $(64,4 \%)$. Conclusion of this study is that there are patients with type 2 diabetes melitus who are also diagnosed with hypertension.
\end{abstract}

Keywords: Prevalence, Diabetes melitus type 2, Hypertension.

\begin{abstract}
Abstrak: Prevalensi Diabetes Melitus Tipe 2 dengan Kejadian Hipertensi di Poliklinik Penyakit Dalam RS Pertamedika Ummi Rosnati. Diabetes melitus tipe 2 menjadi masalah dunia terkait masalah tidak terkontrolnya kadar gula darah. Tetapi jika penyakit ini tidak ditangani dengan baik akan timbul komplikasi, salah satu komplikasi adalah hipertensi, sehingga tujuan penelitian ini untuk mengetahui prevalensi diabetes melitus tipe 2 dengan kejadian hipertensi di poliklinik penyakit dalam RS Pertamedika Ummi Rosnati. Penelitian ini menggunakan metode observasional deskriptif dan pendekatan secara cross sectional dengan sampel yang terdiri dari 126 responden. Teknik pemilihan sampel menggunakan total sampling dengan wawancara terarah. Untuk mengetahui prevalensi digunakan pendekatan deskriptif (analisis univariat). Hasil penelitian didapatkan prevalensi hipertensi pada pasien diabetes melitus tipe 2 sebanyak (46.8\%) dari 126 sampel, prevalensi berdasarkan jenis kelamin perempuan lebih banyak dibandingkan laki laki, yaitu sebanyak (61\%). prevalensi berdasarkan umur didapatkan hasil bahwa sebagian besar pada kelompok usia kelompok usia 40-49 yaitu sebanyak (32.2\%) dan pada kelompok usia 50-59 tahun, yaitu sebanyak (32.2\%). Untuk prevalensi berdasarkan lamanya menderita diabetes melitus tipe 2 sebagian besar telah menderita diabetes melitus tipe 2 sebagian besar penderita diabetes melitus tipe 2 $<5$ tahun yaitu sebanyak (64,4\%). Kesimpulan dari penelitian ini didapatkan adanya pasien diabetes melitus tipe 2 yang juga terdiagnosa hipertensi.
\end{abstract}

Kata Kunci : Prevalensi, Diabetes Melitus Tipe 2, Hipertensi. 


\section{PENDAHULUAN}

Transisi epidemiologis penyebab kematian utama dari penyakit menular menjadi penyakit degeneratif membuat penyakit diabetes melitus yaitu suatu penyakit metabolik yang diwaspadai (International Diabetes Federation, 2017). Diabetes melitus tipe 2 merupakan diabetes melitus yang sering ditemukan pada orang dewasa, ditandai dengan kondisi gula darah tidak terkontrol. Penderita diabetes melitus membutuhkan terapi pengobatan yang lama untuk mengurangi resiko komplikasi. Diabetes menjadi penyakit degeneratif tidak menular yang jumlahnya akan meningkat di masa datang. Estimasi International Diabetes Federation (IDF) pada tahun 2017 terdapat 424 juta orang menderita diabetes dengan usia antara 20-79 tahun. Jumlah tersebut pada tahun 2045 diperkirakan meningkat menjadi 686 juta orang (American Diabetes Association, 2019). World Health Organization (WHO) memprediksi kenaikan jumlah penderita diabetes melitus di Indonesia dari 8,4 juta orang pada tahun 2000 menjadi sekitar 21,3 juta orang pada tahun 2030. Indonesia menempati peringkat ke-5 terbanyak di dunia (Soelistijo et al., 2015). Diabetes melitus tipe 2 menjadi diabetes melitus yang paling umum, terhitung sekitar $90 \%$ dari semua kasus diabetes. Jumlah penderita diabetes melitus di Provinsi Aceh pada tahun 2013 sebesar $1,3 \%$ mengalami peningkatan pada tahun 2018 sebesar 0,4\% (Kementerian Kesehatan Republik Indonesia, 2018).

Diabetes melitus tipe 2 menunjukan gangguan sekresi insulin dan gangguan kerja insulin sehingga terjadi hiperglikemia (Genser et al., 2016). Beberapa penelitian menyatakan bahwa diabetes melitus tipe 2 yang ditandai dengan hiperglikemia berhubungan tinggi dengan terjadinya hipertensi (Grundy, 2016). Dua dari tiga orang penderita diabetes melitus mempunyai tekanan darah tinggi (Pavlou et al., 2018). Di sisi lain hipertensi berhubungan juga dengan terjadinya diabetes (Whelton et al, 2018). American Heart Association (AHA) menyatakan bahwa diabetes melitus merupakan faktor resiko terjadinya hipertensi yang diperantarai oleh umur, jenis kelamin dan lama menderita diabetes melitus (Benetos et al, 2017). Keadaan ini diperkuat dengan terdapatnya penelitian pada penderita diabetes melitus tipe 2 dengan resiko hipertensi yaitu $28 \%$ dan lebih banyak pada wanita yaitu 64\% (Prabowo, 2019).

Pasien Penyakit diabetes dengan hipertensi yang tidak terkontrol berhubungan tinggi dengan munculnya komplikasi serebrovaskular dan kardiovaskular. Penyakit diabetes berhubungan dengan peningkatan resiko stroke, gagal jantung kongestif, penyakit jantung koroner, hingga mengakibatkan kematian (Himmelfarb et al., 2014). Prevalensi diabetes melitus tipe 2 dengan kejadian hipertensi penting untuk diketahui. Peneliti merasa tertarik untuk meneliti prevalensi diabetes melitus tipe 2 dengan kejadian hipertensi di Poliklinik Penyakit Dalam RS Pertamedika Ummi Rosnati.

\section{METODE}

Penelitian ini merupakan penelitian observasi analitik dengan desain penelitian Cross sectional. Penelitian ini dilakukan di poliklinik penyakit dalam RS Pertamedika Ummi Rosnati. Dilaksanakan pada januari s/d Maret 2020. Populasi penelitian ini adalah seluruh pasien diabetes melitus tipe 2 di poliklinik penyakit dalam RS Pertamedika Ummi Rosnati. Sampel penelitian ini diambil secara non probability sampling dengan metode total sampling dengan total responden 126 orang. Variabel independen Diabetes melitus tipe 2, Jenis kelamin, Usia, dan Lama menderita diabetes melitus tipe 2, sedangkan variabel dependen yaitu hipertensi. Penelitian ini menggunakan pengumpulan data secara primer dan sekunder. Data primer dilakukan ketika diagnosis 
diabetes melitus tipe 2 ditegakan oleh dokter pada saat itu, sementra peneliti mengisi kuesioner melalui wawancara dengan pasien untuk mengumpulkan data. Sedangkan data sekunder dikumpulkan melalui rekam medis yang dibacakan oleh dokter dan peneliti melakukan pengumpulan data dengan mengisi kuesioner melalui wawancara langsung dengan pasien untuk mengumpulkan data. Pengolahan data yang diperoleh dari hasil penelitian diolah secara manual dengan mengelompokan hasil observasi kemudian dilakukan perhitungan dan dianalisis. Data dianalisis menggunakan analisis univariat untuk melihat distribusi dan frekuensi variabel independen dan dependen.

\section{HASIL}

Tabel 1. Karakteristik Responden Berdasarkan Umur, Jenis Kelamin, Lama Mengidap Diabetes Melitus Tipe 2

\begin{tabular}{ccc}
\hline Karakteristik responden & Jumlah (n) & Presentase(\%) \\
\hline Kelompok usia & 2 & \\
$20-29$ & 6 & 4.6 \\
$30-39$ & 42 & 33.3 \\
$40-49$ & 54 & 42.9 \\
$50-59$ & 22 & 17.5 \\
$\geq 60$ & 126 & $100 \%$ \\
\hline Jumlah & & \\
Jenis Kelamin & 51 & 40.5 \\
Laki_laki & 75 & 59.5 \\
Perempuan & 126 & $100 \%$ \\
\hline Jumlah & & \\
\hline Lama mengidap Diabetes & & 48.4 \\
Melitus Tipe 2 & 61 & 32.6 \\
<5 Tahun & 41 & 19 \\
5-10 Tahun & 24 & $100 \%$ \\
>10 Tahun & 126 & \\
\hline Jumlah & &
\end{tabular}

Berdasarkan table 1 diatas didapatkan data karakteristik didapatkan 126 orang menderita Diabetes Melitus Tipe 2. Pada penderita diabetes melitus tipe 2 Usia yang paling banyak menderita diabetes melitus tipe 2 adalah kelompok usia 50-60 tahun, yaitu sebanyak 54 orang $(42.9 \%)$. pasien berjenis kelamin perempuan, yaitu sebanyak 75 orang $(59.5 \%)$, sedangkan yang berjenis kelamin laki laki 51 orang (40.5\%). Sebagian besar responden, yaitu 61 orang (48.4\%) menderita diabetes melitus tipe 2 kurang dari 5 tahun.

Tabel 2. Prevalensi Tekanan Darah Pada Pasien Diabetes Melitus Tipe 2

\begin{tabular}{ccc}
\hline Tekanan darah & $\mathbf{N}$ & $\mathbf{\%}$ \\
\hline Normal & 67 & 53.2 \\
Hipertensi & 59 & 46.8 \\
\hline Jumlah & 126 & 100 \\
\hline
\end{tabular}

Berdasarkan tabel 2 menunjukan bahwa dari seluruh pasien diabetes melitus tipe 2 yaitu 126 orang, yang menderita hipertensi sebanyak 59 orang
$(46.8 \%)$, sedangkan pasien diabetes melitus tipe 2 yang memiliki tekanan darah yang normal sebanyak 67 orang (53.2\%). 
Tabel 3. Prevalensi Hipertensi Pada Pasien Diabetes Melitus Tipe 2 Berdasarkan Jenis Kelamin

\begin{tabular}{ccc}
\hline Jenis Kelamin & $\mathbf{N}$ & $\mathbf{\%}$ \\
\hline Laki-Laki & 23 & 39 \\
Wanita & 36 & 61 \\
\hline Jumlah & 59 & 100 \\
\hline
\end{tabular}

Berdasarkan tabel 3 menunjukan hasil bahwa dari 59 pasien diabetes melitus tipe 2 yang terdiagnosa hipertensi, sebagian besar terjadi pada pasien berjenis kelamin perempuan, yaitu sebanyak 36 orang $(61 \%)$ dan yang berjenis kelamin laki laki sebanyak 23 orang (39\%).

Tabel 4. Prevalensi Hipertensi Pada Pasien Diabetes Melitus Tipe 2 Berdasarkan Usia

\begin{tabular}{ccc}
\hline Usia & $\mathbf{N}$ & $\mathbf{\%}$ \\
\hline 20-29 Tahun & 4 & 6.8 \\
30-39 Tahun & 9 & 15.3 \\
40-49 Tahun & 19 & 32.2 \\
50-59 Tahun & 19 & 32.2 \\
$\geq 60$ Tahun & 8 & 13.6 \\
\hline Jumlah & 59 & 100 \\
\hline
\end{tabular}

Berdasarkan tabel 4 menunjukkan bahwa dari semua pasien diabetes melitus tipe 2 yang terdiagnosa hipertensi, yaitu sebanyak 59 orang, didapatkan bahwa sebagian besar berada di kelompok usia 40-49 tahun yaitu sebanyak 19 orang
(32,2\%) dan kelompok usia 50-59 tahun yaitu sebanyak 19 orang (32.2\%), serta yang paling rendah pada kelompok usia 20-29 tahun yaitu sebanyak 4 orang $(6.8 \%)$.

Tabel 5. Prevalensi Hipertensi Pada Pasien Diabetes Melitus Tipe 2 Berdasarkan Lamanya Menderita Diabetes Melitus Tipe 2

\begin{tabular}{ccc}
\hline $\begin{array}{c}\text { Lamanya Menderita } \\
\text { DM }\end{array}$ & $\mathbf{N}$ & \% \\
\hline 5 Tahun & 38 & 64.4 \\
5-10 Tahun & 14 & 23.7 \\
$>$ 10 Tahun & 7 & 11.9 \\
\hline Jumlah & 59 & 100 \\
\hline
\end{tabular}

Berdasarkan tabel 5 menunjukkan bahwa dari semua pasien diabetes melitus tipe 2 yang terdiagnosa hipertensi, yaitu sebanyak 59 orang, serta didapatkan

\section{PEMBAHASAN}

Berdasarkan

penelitian karakteristik responden di poliklinik penyakit dalam RS Pertamedika Ummi Rosnati yaitu sebagian besar berusia 50-60 tahun (42,9\%). Sebagian besar berjenis kelamin perempuan $(59,5 \%)$. sebagian besar terdiagnosa hipertensi dengan lama menderita diabetes melitus tipe 2 selama $<5$ tahun, yaitu sebanyak 38 orang $(64,4 \%)$.

Lama mengidap diabetes melitus tipe 2 sebagian besar pada kelompok <5 tahun $(48,4 \%)$.

Berdasarkan hasil penelitian ini didapatkan sebanyak 126 orang menderita diabetes melitus tipe 2, 
sedangkan sebanyak 59 (46.8\%) orang terdiagnosa hipertensi, Hasil ini sesuai dengan penelitian sebelumnya yang melaporkan terdapat $(36.1 \%)$ penderita diabetes melitus tipe 2 dengan hipertensi, di desa Tanjung Dayang Kabupaten Ogan Ilir (Febriani and Fitri, 2019). Hipertensi pada diabetes melitus tipe 2 dapat terjadi karena kadar gula darah yang tinggi akan menyebabkan gula darah menempel pada dinding pembuluh darah. Keadaan ini akan merusak bagian dalam dinding pembuluh darah yang akan menyebabkan terjadinya proses inflamasi. Keadaan ini menyebabkan dinding pembuluh darah menjadi keras, kaku dan akhirnya menyebabkan terjadinya penyumbatan yang berakibat terhadap perubahan tekanan darah yang dinamakan hipertensi (Ayu et al., 2019).

Dari hasil penelitian ini diketahui bahwa jumlah pasien diabetes melitus tipe 2 sebanyak 126 orang dan yang menderita diabetes melitus tipe 2 dengan hipertensi sebanyak 58 orang, dimana pasien perempuan lebih banyak yaitu 36 $(61 \%)$ orang dibandingkan dengan pasien laki laki 23 (39\%) orang, Hasil ini sesuai dengan hasil penelitian sebelumnya yang melaporkan prevalensi perempuan penderita diabetes melitus tipe 2 dengan hipertensi lebih tinggi $(68.05 \%)$ dibandingkan dengan laki laki (31.9\%), penelitian ini dilakukan menggunakan data dari Riskesdas dengan wilayah penelitian 33 provinsi di Indonesia, pada 5253 pasien diabetes melitus tipe 2 (Sihombing et al., 2017). Temuan ini sesuai dengan penelitian sebelumnya yang menyatakan bahwa jenis kelamin wanita signifikan berhubungan dengan hipertensi pada pasien diabetes melitus tipe 2, dengan meningkatkan kadar lemak dalam tubuh perbedaan jenis kelamin menentukan perbedaan struktur organ dan hormon. Pada jenis kelamin perempuan terdapat hormon estrogen yang berperan dalam meningkatkan kadar High Density Lipoprotein (HDL), seiring dengan pertambahan usia disertai dengan diabetes melitus tipe 2 produksi estrogen cepat menurun, oleh karena itu perempuan lebih rentan mengalami menderita diabetes melitus tipe 2 yang hipertensi setelah berusia diatas 45 tahun dan setelah mengalami menopause (Soubra et al., 2016).

Dari hasil penelitian ini didapatkan pasien diabetes melitus tipe 2 yang juga terdiagnosa hipertensi, proporsi paling banyak didapat pada kelompok usia 40-49 tahun (32.2\%) dan pada kelompok usia 50-59 tahun $(32.2 \%)$. Hasil ini sesuai dengan yang dilaporkan sebelumnya, melaporkan jumlah tertinggi pasien diabetes melitus tipe 2 dengan hipertensi terdapat pada kelompok umur 41-60 tahun $(53.5 \%)$, penelitian ini dilakukan pada 118 penderita diabetes melitus tipe 2 di kota Benghazi (Nouh et al., 2017). Penuaan pada penderita diabetes melitus tipe 2 umumnya terkait dengan penurunan berbagai fungsi tubuh. Penurunan fungsi pada penderita diabetes melitus tipe 2 dapat menyebabkan perubahan struktur pembuluh darah seperti penyempitan lumen, serta dinding pembuluh darah menjadi kaku dan elastisitasnya berkurang sehingga meningkatkan tekanan darah, menyebabkan beban pada arteri semakin besar dan tekanan darah naik (Winta et al., 2018).

Hasil penelitian ini didapatkan bahwa dari 59 pasien diabetes melitus tipe 2 yang terdiagnosa hipertensi, diketahui bahwa 38 (64.4\%) orang telah menderita diabetes melitus tipe 2 kurang dari 5 tahun. Temuan ini sesuai dengan penelitian yang dilakukan sebelumnya, yang melaporkan bahwa secara teoritis terjadi peningkatan tekanan darah akibat perubahan fungsional endotel pada pasien diabetes melitus tipe 2 memerlukan kurang dari 5 tahun. Lamanya durasi diabetes melitus tipe 2 terjadi paparan hiperglikemia yang lama pada pembuluh darah menyebabkan terjadinya komplikasi pada mikrovaskular maupun makrovaskular. Penelitian sebelumnya melaporkan kadar gula darah yang terus-menerus tinggi dapat merusak pembuluh darah menyebabkan terjadinya lesi aterosklerosis. Terjadinya aterosklerosis pada pembuluh darah 
dalam jangka panjang dapat memicu peningkatan tekanan darah (Prenner

\section{KESIMPULAN}

Karakteristik responden di poliklinik penyakit dalam RS Pertamedika Ummi Rosnati yaitu sebagian besar berusia 5060 tahun (42,9\%). Sebagian besar berjenis kelamin perempuan (59,5\%). Lama mengidap diabetes melitus tipe 2 sebagian besar pada kelompok $<5$ Tahun $(48,4 \%)$. Prevalensi hipertensi pada pasien diabetes melitus tipe 2 di poliklinik penyakit dalam RS Pertamedika Ummi Rosnati sebanyak 59 orang (46.8\%) dari 126 orang yang menderita diabetes melitus tipe 2. Prevalensi hipertensi pada pasien diabetes melitus tipe 2 berdasarkan jenis kelamin di poliklinik penyakit dalam RS Pertamedika Ummi Rosnati lebih banyak terjadi pada perempuan, yaitu sebanyak 36 orang (61\%) dan pada laki laki sebanyak 23 orang (39\%). Prevalensi hipertensi pada pasien diabetes melitus tipe 2 berdasarkan usia di poliklinik penyakit dalam RS Pertamedika Ummi Rosnati sebagian besar terjadi pada kelompok usia 40-49 yaitu sebanyak 19 (32.2\%) orang dan pada kelompok usia 50-59 tahun, yaitu sebanyak 19 orang (32.2\%). Prevalensi hipertensi pada pasien diabetes melitus tipe 2 berdasarkan lama menderita diabetes melitus tipe 2, sebagian besar telah menderita diabetes melitus tipe $2<5$ tahun yaitu sebanyak 36 orang $(64,4 \%)$.

\section{SARAN}

Penelitian ini diharapkan dapat memberikan informasi kepada rumah sakit mengenai prevalensi penderita diabetes melitus tipe 2 yang mengalami hipertensi. Selain itu sebagai informasi karakteristik penderita diabetes melitus tipe 2 yang mengalami hipertensi. Penelitian ini diharapkan dapat menjadi sumber rujukan. serta diharapkan dalam penelitian selanjutnya dibahas mengenai hubungan diabetes melitus tipe 2 dengan kejadian hipertensi. Penelitian ini diharapkan dapat memberikan informasi tentang prevalensi diabetes melitus tipe 2 dengan kejadian hipertensi, Selain itu penelitian ini juga diharapkan memberi and Chirinos, 2015).

wawasan lebih kepada penderita diabetes melitus tipe 2 mengenai seringnya kejadian hipertensi sebagai komplikasi diabetes melitus tipe 2. Perlu diadakan lagi penelitian lebih lanjut dengan penambahan variabel konsumsi obat dan aktifitas fisik. Selain itu, perlu penelitian lebih lanjut untuk mengetahui hubungan antara variabel-variabelnya.

\section{UCAPAN TERIMAKASIH}

$\begin{array}{ccc}\text { Ucapan } & \text { terima } & \text { kasih ini } \\ \text { disampaikan } & \text { kepada } & \text { Fakultas }\end{array}$ Kedokteran Universitas Abulyatama dan RS Pertamedika Ummi Rosnati yang telah mendukung pelaksanaan penelitian.

\section{DAFTAR PUSTAKA}

American Diabetes Association. (2019). Standards of Medical Care in Diabetes 2019. Diabetes Care 42(1):1-193.

Ayu, I., Wirawati, P., Mahartini, N.N. (2019). Hubungan kadar gula darah dengan hipertensi pada pasien diabetes melitus tipe $2 \mathrm{di}$ RSUP Sanglah. Intisari Sains Medis 10(3): 797-800.

Benetos, A., Davis, A.M., Michos, E.D., Muntner, P., Rossing, P., Zoungas, S., et al. (2017). Diabetes and Hypertension: A Position Statement by the American Diabetes Association. Diabetes Care 40(9): 2-3.

Febriani, R., Fitri, M. (2019). Analisis Kejadian Hipertensi pada Lansia dengan Diabetes Melitus. J 'Aisyiyah Med 4(3): 256-273.

Genser, L., Rossario, J., Mariolo, C., Castagneto-gissey, L., Panagiotopoulos, S. (2016). Obesity, Type2 Diabetes, and the Metabolic Syndrome Pathophysiologic Relationships and Guidelines for Surgical Intervention Laurent. Surg Clin North Am 96(4): 681-701.

Grundy, S.M. (2016). Metabolic syndrome update. Trends 
Cardiovasc Med 26(4): 364-373.

Himmelfarb, C.D., Handler, J., Lackland, D.T. (2014). Evidence-Based Guideline for the Management of High Blood Pressure in Adults Report From the Panel Members Appointed to the Eighth Joint National Committee (JNC 8). J Am Med Assoc 311(5): 1-14.

International Diabetes Federation. (2017). IDF Diabetes Atlas. 8th ed. Brussels, Belgium: WHO.

Kementerian Kesehatan Republik Indonesia. (2018). Riset Kesehatan Dasar. Jakarta: Riskesdas.

Nouh, F., Omar, M., Younis, M. (2017). Prevalence of Hypertension among Diabetic Patients in Benghazi: A Study of Associated Factors. Asian J Med Health 6(4): 1-11.

Pavlou, D.I., Paschou, S.A., Anagnostis, P., Spartalis, M. (2018). Maturitas Hypertension in patients with type 2 diabetes melitus: Targets and management. Maturitas 112(1): 71-77.

Prabowo, R.H. (2019). Prevalensi Hipertensi Pada Pasien Diabetes Melitus. J Biomedika 12(01): 41-46.

Prenner, S.B., Chirinos, J.A. (2015). Arterial Stiffness in Diabetes Melitus. Atherosclerosis 238(2): 370-379.

Sihombing, M., Sumber, P., Kesehatan, P. (2017). Faktor yang Berhubungan dengan Hipertensi pada Penduduk Indonesia yang Menderita Diabetes Melitus (Data Riskesdas 2013). Buletin Penelitian Kesehatan 7(3): 5364.

Soelistijo SA, Novida H, Rudijanto A, Soewondo P. (2015). Pengelolaan Dan Pencegahan Diabetes Melitus Tipe 2 Di Indonesia 2015. Jakarta: Perkeni.

Soubra, L., Nureddin, H., Omar, A.G., Saleh, M. (2016). Factors Associated with Hypertension
Prevalence and Control among Lebanese Type 2 Diabetic Patients. Int J Pharm Pharm Sci 8(10): 153-159.

Whelton, P.K., Carey, R.M., Aronow, W.S., Casey, D.E., Collins, K.J., Himmelfarb, D.E., et al. (2018). Clinical Practice Guideline 2017 ACC / AHA / AAPA / $A B C$ / ACPM / AGS / APhA / ASH / ASPC / NMA / PCNA Guideline for the Prevention, Detection, Evaluation, and Management of High Blood Pressure in Adults A Report of the American College of Cardiology /. New York: JNC.

Winta, A.E., Setiyorini, E., Wulandari, N.A. (2018). Hubungan Kadar Gula Darah dengan Tekanan Darah pada Lansia Penderita Diabetes Tipe 2. J Ners dan Kebidanan 5(2): 163-171. 